Thorax, 1979, 34, 819-821

\title{
Simultaneous penetrating wounds of the myocardium and aorta caused by firearms: surgical treatment
}

\author{
R LODI, ${ }^{1}$ A BONDIOLI, ${ }^{1}$ G DOMENICHINI, ${ }^{2}$ C MAZZETTI, ${ }^{2}$ U MORANDI, ${ }^{1}$ L BONATI, ${ }^{1}$ \\ AND J J BYRNES \\ From the Department of Surgical Semeiotics and Division of Thoraco-Pulmonary Surgery, ${ }^{1}$ and the \\ Department of Cardiovascular Diseases and Division of Cardiology of the University of Modena, Modena, Italy
}

The frequency of trauma and penetrating wounds of the heart and the great intrathoracic vessels is continuously increasing. In peacetime heart wounds constitute about $3 \%$ of all penetrating wounds of the chest. About $40 \%$ of patients with penetrating wounds of the heart reach hospital alive. If these patients undergo an immediate pericardiocentesis and operation they have an $80-90 \%$ chance of survival. In a study of cases of penetrating gunshot wounds of the heart and aorta 31 patients died immediately while five survived for at least 30 minutes (Parmley et al, 1958).

We present a case of simultaneous penetrating gunshot wounds of the myocardium and thoracic aorta when the patient survived more than 30 minutes and was successfully treated surgically. Repeated assessment during the four years since the injury has not shown any late complications.

\section{Case report}

A white 52-year-old man was brought to the emergency room with a gunshot wound. The entry point of the projectile was in the left fourth intercostal space on the midclavicular line. The point of entry into the chest and the severity of the state of haemorrhagic shock led us to suspect a lesion of the heart or the aorta. A preoperative radiographic examination of the chest showed an increased heart shadow and mediastinal widening, a haemothorax, and the presence of a projectile in the left paracardiac region adjacent to the vertebral column. The arterial blood pressure was $60 \mathrm{mmHg}$ during continuous blood transfusion and the central venous pressure $30 \mathrm{cmH}_{2} \mathrm{O}$. An electrocardiogram showed an alteration of ventricular repolarisation with notable raising of the S-T segment, and bradycardia.

An emergency thoracotomy was performed through an incision in the fifth left intercostal space. Initial inspection of the thoracic cavity showed a haemothorax, haemomediastinum, and haemopericardium. By opening the pericardium, which contained $400 \mathrm{cc}$ of blood, we could see two lesions of the myocardium - one on the anterior wall of the right ventricle near the anterior descending branch of the left coronary artery and the other a few centimetres from the apex of the left ventricle (fig 1). The greatest loss of blood was from the wound of the right ventricle. Digital

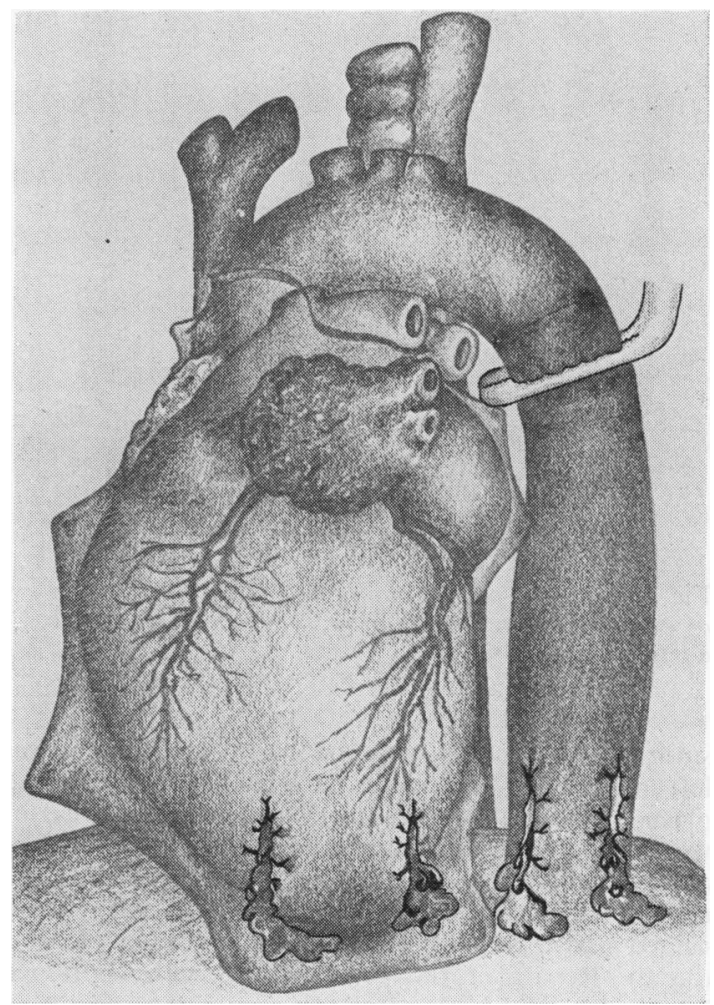

Fig 1 Drawing showing two cardiac and two aortic wounds. Total clamping of aorta during initial period of operation for repair of posterior aortic wound.

control of the two myocardial wounds resulted in the resumption of more efficient, rhythmic contraction of the heart.

Further inspection of the thoracic cavity led to the discovery of a large periaortic haematoma caused by two perforations of the thoracic aorta, one anteriorly and one posteriorly at the level of the inferior pul. monary vein. Because of the impossibility of performing left heart bypass advantage was taken of the degree of hypothermia $\left(34^{\circ} \mathrm{C}\right)$ and hypovolaemic hypotension $(60 \mathrm{mmHg})$ of the patient. The aorta was totally clamped just above the wounds allowing direct 


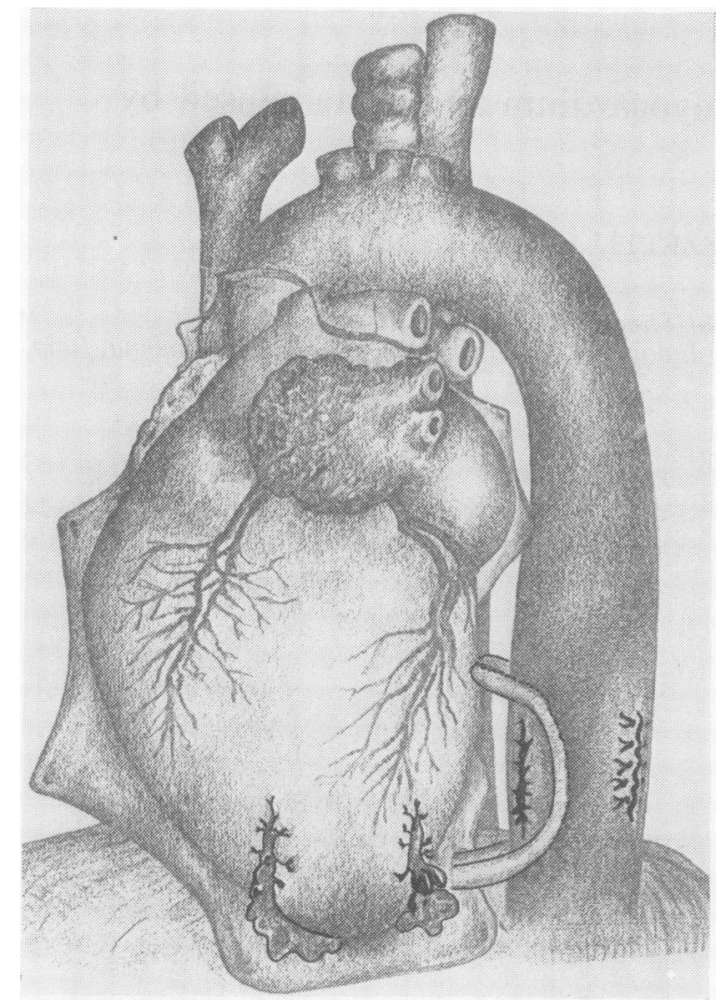

Fig 2 Lateral, partial clamping of aorta for repair of anterior aortic wound after removal of proximal aorta clamp.

suture of the posterior wound (fig 1). The clamp was left in place for 15 minutes. A second clamp was then placed tangentially on the aorta to exclude the anterior wound and the first clamp was removed (fig 2). The anterior wound was repaired with a Teflon patch. The myocardial wounds were then repaired with interrupted mattress sutures buttressed by Teflon pledgets (fig 3). Repair of the myocardium, with continued transfusion of blood, resulted in an improvement in the state of shock and an increase in body temperature.

The projectile responsible for the lesions of the myocardium and the aorta was found next to the vertebral column, under the aorta. A lesion of the musculature of the oesophagus was also noted and repaired. The pericardium was then partially closed and drained. The thorax was closed in the usual manner. The postoperative course was satisfactory, apart from pyrexia. There was no evidence of any neurological, renal, or hepatic damage. The patient was allowed home after 20 days.

During the next four years the patient underwent regular radiographic, electrocardiographic, and phonocardiographic examinations as well as stress tests, none of which indicated any complications or sequelae related to the operation.

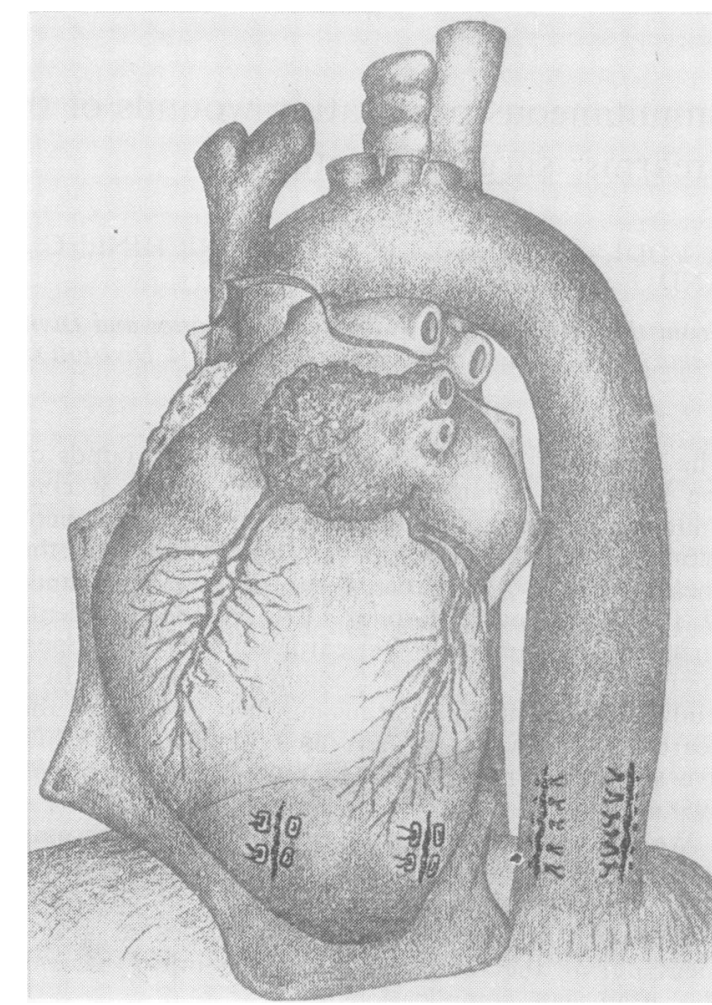

Fig 3 Final aspect of myocardial and aortic repair.

\section{Discussion}

When a laceration of the myocardium or the great $x$ vessels is suspected immediate exploratory operation is $\frac{0}{3}$ always advisable.

Surgery should not be delayed because the signs of $\delta$ cardiac tamponade are not present. These are incon- 3 sistent, and develop in only a small proportion of $\mathrm{O}$ cardiac gunshot wounds. Pericardiocentesis is of doubtful efficacy and may provide misleading information (Tarantino et al, 1978). Urgent thoracotomy permits control of haemorrhage and repair of these potentially $N$ lethal injuries, with a chance of survival not afforded $N$ by treatment confined to simple resuscitative measures, $N$ such as pericardiocentesis, respiratory assistance, and $\omega$ blood volume replacement.

The availability of equipment for performing totalo or partial cardiopulmonary bypass should not be con- $\frac{\mathbb{C}}{\mathbb{N}}$ sidered a limiting factor when deciding whether or $\stackrel{?}{?}$ not to perform an emergency operation. By taking 0 advantage of certain conditions present in the patient at operation, such as hypothermia and hypotension, $\overrightarrow{\mathbb{D}}$ as we did in this case, or by inducing cardiac fibril- $\frac{O}{\mathbb{D}}$ lation with subsequent intermittent cardiac massage, $\stackrel{\Phi}{\varrho}$ or briefly clamping the venae cavae, repair of penetrating wounds of the heart and aorta can proceed 8 
without resort to complete or partial cardiopulmonary bypass. A coronary-aortic bypass is necessary to repair wounds of the coronary vessels.

We thank Dr Bompani of the division of cardiology for his work on the figures.

\section{References}

Parmley, L F, Manion, W L, Mattingly, T W (1958). Non-penetrating traumatic injury of the heart. Circulation, 18, 371-396.
Tarantino, A M, Gentili, G, and Moltoni, G (1978). Ferita del ventricolo destro da punto e taglio: considerazioni cliniche e terpeutiche. Chirurgia Toracica, 31, 57-61.

Requests for reprints to: Professor Renzo Lodi, Direttore-Semeiotica Chirurgica e Div di Chirurgia Toraco-Polmonare, Policlinico di Modena, Via del Pozzo, 71, 41100 Modena. 